\title{
Biotherapies: Are they Just Like any Other Drugs?
}

\author{
Gilles Paintaud ${ }^{1}$, Dominique Tonelli ${ }^{2}$, Eric Postaire ${ }^{3}$ and the participants in Round Table $N^{\circ}$ 5, Giens XXII \\ 1 Université François Rabelais Tours, EA 3853, France; CHRU de Tours, Pharmacologie, Tours, France \\ 2 BMS, Rueil Malmaison, France \\ 3 Ministère de l'Éducation Nationale, de la Recherche et de l'Enseignement Supérieur, France ; Inserm, Paris, France
}

\begin{abstract}
Keywords:
biotherapies;

biopharmaceuticals;

monoclonal antibodies;

cell therapy;

gene therapy

Abstract - "Biotherapies" include both biopharmaceuticals and cell and gene therapies. Biopharmaceuticals are macromolecules created by biotechnologies. In the case of monoclonal antibodies, the starting dose to be given to Humans is difficult to select because there may be no relevant animal model. At the time of registration, the knowledge of the mechanism of action of monoclonal antibodies is insufficient and cohort follow up studies are needed. Genetic predisposition and pharmacokinetics are interindividual sources of variability. Some of the adverse drug reactions are predictable but others are unexpected or even paradoxical. Cell and "ex vivo" gene therapies consist in the manipulation of collected cells and their infusion in autologous or allogenic clinical settings. The methodology of the clinical development of drugs cannot be readily applied to these therapies. On the other hand, "in vivo" gene therapy uses vectors or macromolecules which can be considered as biopharmaceuticals.
\end{abstract}

\section{Introduction}

The objective of Giens 2006 Round Table No. 5 was to answer the following question: can biotherapies be considered to be just like any other drugs? The term "biotherapies" is often used to describe biopharmaceuticals, cell therapy and gene therapy.

- Biopharmaceuticals differ from conventional medicinal products that are small chemically synthesized molecules or molecules obtained by extraction, usually from plants. Biopharmaceuticals are complex macromolecules produced by biotechnologies by genetic manipulation of living organisms. ${ }^{[1]}$ By extension, this terminology is also applied to certain highly purified extraction products (apart from plants): hGH [human Growth Hormone], FSH [Follicule Stimulating Hormone], LH [Luteinizing Hormone], insulin, etc. However, these extractive molecules were not discussed during this round table. In contrast with biological therapies, biopharmaceuticals are inert molecules.

- Cell therapy using haematopoietic stem cells (HSC) differs from medicinal products in that it uses "tailor-made" products, created for a given patient, a field in which few manufacturers are currently involved. For other ex vivo cell therapy and

\footnotetext{
* For a list of participants, please see the end of the article.
}

gene therapy products, involving industrial structures, evaluation of the quality of the product is based on reproducibility of the manufacturing process. As for medicinal products, Afssaps (French medicines agency) is responsible for ensuring the quality, reproducibility, safety and efficacy in Man.

During round table preparation meetings, it was decided to:

- focus on therapeutic antibodies and fusion proteins, which are biopharmaceuticals raising specific problems, as this type of biopharmaceutical has been on the market for several years and a very large number of monoclonal antibodies and fusion proteins are currently in the pipeline. A preliminary assessment of these agents is therefore possible and necessary;

- and discuss cell therapy and gene therapy in order to evaluate the difficulties encountered and to evaluate the possibility of applying the same type of clinical development as that used for medicinal products.

\section{Therapeutic antibody and fusion proteins}

\subsection{Preclinical studies}

The example of TGN1412 (from TeGenero), which induced serious adverse effects in healthy subjects during a phase 1 study ${ }^{[2]}$ 
was discussed. The audit performed by the United Kingdom Medicines agency did not demonstrate any defect in the preclinical procedure. ${ }^{[3]}$ The animal species considered to be the most relevant was the Cynomolgus monkey, as its antigen CD28 is similar if not identical to that of Man. ${ }^{[4]}$ Very few monkeys were studied (2-3 of each sex), but this is a classical procedure for this type of study. However, a larger number of animals should usually be studied because these monkeys, like Man, present genetic polymorphisms. The relevance of the animal model should also have been tested by a cell biology study on monkey cells. Finally, this antibody is a super-agonist, which distinguishes it from all antibodies currently on the market, designed to inhibit their target or induce cytolytic effects. Knowledge on the biological actions of TGN1412 may therefore have been insufficient.

Antibodies are bivalent molecules: their variable portion binds to the target antigen but the Fc portions also has an action by recruiting immune effectors. Relevant animal models may therefore not exist ${ }^{[5]}$, due to:

- phylogenetic differences between Man and monkeys, especially with Cercopithecidae like Cynomolgus monkeys, which are frequently studied. These differences indicate the need for greater caution;

- transgenic mouse models cannot have, in addition to the human target antigen, the human form of all immune effectors (complement fractions, receptors present on the surface of cytotoxic cells, etc.).

Preclinical studies must therefore be adapted as closely as possible to the supposed characteristics of the therapeutic antibody. Chronic toxicology studies should also be performed more systematically in view of the frequent long-term use of therapeutic antibodies.

\subsection{Phase I}

Due to the limited relevance of animal models, it is difficult to define the first dose to be administered to Man. There are no international recommendations on this point, although it has been the subject of a FDA (food and drug agency) guidance. ${ }^{[6]}$ At the time of the round table, the most recent document was an Afssaps note for guidance issued in September 2006, describing the choice of the first dose, the dose progression methodology and the administration protocol in volunteers. ${ }^{[7]}$ This text indicates that "The first dose administered (...) must not induce any detectable toxic effect in the short term". The first dose can be calculated from the No Adverse Observed Effect Level (NOAEL) or from the No Observed Effect Level (NOEL), measured in the relevant species in terms of metabolism or, for biopharmaceuticals, in terms of pharmacological activity. The first dose to be administered in man is the NOAEL or the NOEL, corrected by an allometric factor for scaling from animals to Man and divided by a safety factor $(\geq 10)$. In the case of biopharmaceuticals, the Afssaps note for guidance recommends use of the NOEL and not the NOAEL. ${ }^{[7]}$

If the monoclonal antibody is tested in phase 1 immediately in patients, patients must be selected according to expression of the therapeutic target (for example, the efficacy of trastuzumab requires overexpression of receptor HER-2). Nevertheless, the term "targeted therapy" sometimes used to describe therapeutic monoclonal antibodies, does not have any scientific basis. These biopharmaceuticals can have several types of pharmacodynamic effects and various adverse effects, if only because of the presence of the target antigen on various tissues. It therefore does not constitute a more targeted treatment than conventional drugs. Furthermore, for new therapeutic antibodies with an affinity for a known target (a new anti-TNF-alpha [TNF = Tumor Necrosis Factor $]$ or a new anti-CD20), a "me-too drug" logic does not apply: they must be considered to be new biopharmaceuticals because their effects can be very different.

In view of the difficulties involved in the choice of the dose, a complementary scientific expertise, especially immunological, is necessary to identify risks before administration in Man and to help define the first dose to be administered. Phase I should also be longer in order to: (i) gradually increase the doses (sometimes starting with microdoses); (ii) evaluate a longer exposure duration for each dose level; (iii) study patients in more detail (obviously in terms of pharmacokinetics, but also in terms of biological markers); (iv) study administrations on the longer term because of the long half-life of therapeutic antibodies (usually 2 to 3 weeks) and the future chronic administration of the antibody, which is increasingly frequent, as short-term safety is not predictive of long-term safety.

In the case of anticancer biopharmaceuticals, the Optimal Biological Dose must be defined, rather than the Maximum Tolerated Dose used for conventional cytotoxic drugs.

Since the round table, the recommendations of an expert scientific group on phase 1 trials have been published on-line by the United Kingdom Department of Health. ${ }^{[8]}$

\subsection{Clinical development and marketing authorisation}

When a Marketing Authorisation is granted, knowledge on the therapeutic antibody is often incomplete as development has generally been accelerated (especially for serious diseases), the mechanism of action has been only partially elucidated (due to the novelty of the target) and the immunological effects (related particularly to its Fc portion) are still poorly defined. For this reason: (i) optimization of its administration (dose and treatment regimen) and possible drug combinations require complementary 
trials; (ii) the line of treatment can also change and, for example in the case of cancer treatment, move from third-line treatment to second-line and then first-line, or even adjuvant preventive treatment of relapse; (iii) and the role of the target must be re-analysed. This is the case, for example, of cetuximab, which is indicated in the treatment of tumours overexpressing EGFR (epidermal growth factor receptor), while studies showed that this overexpression may not be necessary for its efficacy). ${ }^{[9]}$

\subsection{Evaluation by the Transparency Commission of the "Haute Autorité en Santé" (Health Authority)}

During evaluation by the Transparency Commission, and in view of the often rapid development of the biopharmaceutical, it may be difficult to justify the nature of the comparator (often absent or obsolete) and define the magnitude of the population to be treated, as the necessary epidemiological data are often lacking and may be difficult to obtain, especially when they require molecular biology studies (expression/overexpression of a target in a population of patients) or when determining, for example, the number of patients who cannot be treated by chemotherapy.

\subsection{Phase $\mathrm{IV}$}

For the reasons indicated above and for other reasons, such as the presence of other diseases and therefore concomitant treatments or the less standardized follow-up of "non-trial" patients, there will be a difference between the clinical trial populations and the patients actually treated with the therapeutic antibody. Postmarketing follow-up patient cohorts must therefore be established. These studies nevertheless raise a number of problems: the objective of follow-up of the cohort is not always described sufficiently precisely by regulatory authorities and the practitioners involved in the follow-up of these patients may not be familiar with this type of study. Academic scientists stress the value of systematically establishing biological collections for pharmacogenetic and biological marker studies in order to improve knowledge of the biopharmaceutical.

In fact, studies have shown that the efficacy of rituximab (anti-CD20), ${ }^{[10]}$ infliximab (anti-TNF-alpha) ${ }^{[11]}$ and an anti-RhD monoclonal antibody developed for the prevention of foetomaternal alloimmunization, ${ }^{[12]}$ are influenced by polymorphisms of Fc receptors, and especially Fc $\gamma \mathrm{RIII}$, i.e. by the subject's genetic constitution. These genetic factors account for part of the interindividual variability of response to therapeutic antibodies and could therefore be used for individual tailoring of treatment. Another source of variability of response between patients is the interindividual pharmacokinetic variability observed for monoclonal antibodies and fusion proteins as for "conventional" drugs. ${ }^{[13]}$ Part of this variability is related to weight or can be explained by the development of antibodies directed towards the therapeutic antibody, observed for example with infliximab ${ }^{[14]}$ and rituximab. Drug interactions also exist, as concomitant treatment with methotrexate increases infliximab concentrations in patients treated for rheumatoid arthritis. ${ }^{[15]}$ However, the great majority of this pharmacokinetic variability remains unexplained. ${ }^{[16,17]}$ It is relevant, as the patients with a better clinical response to infliximab, ${ }^{[14,16]}$ etanercept, ${ }^{[18]}$ rituximab, ${ }^{[19,20]}$ or alemtuzumab ${ }^{[21]}$ are those with the highest serum concentrations. Patients treated by these biopharmaceuticals could therefore benefit from individual dose adjustment based on therapeutic drug monitoring when concentration-effect relationships have been more clearly defined.

The adverse effects of therapeutic antibodies were discussed in the light of the example of anti-TNF-alpha agents, which present two characteristics: cytokine inhibitors and therapeutic antibodies with immunological effects because of the Fc portion. Some adverse effects are predictable, such as reactivation of tuberculosis, development of cancers in the long term, etc., but some adverse effects are unexpected (Gram-positive bacterial infections, cancers occurring soon after starting treatment), or even paradoxical (demyelinating diseases, psoriasis, vasculitis, etc.). Prescribers must therefore be given sufficient information and the current information could be improved, as:

- animal studies and pharmacokinetic studies should be described in more detail in SPC (summaries of product characteristics);

- continuing medical training must be reinforced in this field;

- more rapid changes of SPC would be useful when new data on the biopharmaceutical relevant to prescription or patient follow-up are acquired.

\section{Cell therapy and gene therapy}

This subject was discussed in less detail by the round table. This term actually corresponds to two distinct fields: ex vivo cell and gene therapies and in vivo gene therapy.

\section{1. Ex vivo cell and gene therapies}

The cells, obtained from a sample or a donor, are manipulated, possibly genetically modified, conditioned and finally reinjected into the patient. The gene modification can be, for example, introduction in the $\mathrm{T}$ cells lymphocytes of a donor, of a suicide gene able to transform at the intracellular level ganciclovir into a nucleosidic analog in order to prevent graft versus host disease 
Table I. Therapeutic antibodies compared to conventional medicinal products.

\begin{tabular}{|c|c|c|}
\hline & Points in common & Differences \\
\hline Development & They are drugs & \\
\hline Routes of administration & & Parenteral \\
\hline \multirow[t]{2}{*}{ Clinical use } & Existence of drug interactions & Immunogenicity \\
\hline & Existence of adverse effects & Immunotoxicity \\
\hline \multirow[t]{3}{*}{ Pharmacokinetics } & Existence of interindividual variability & $\begin{array}{l}\text { Mechanisms of absorption, } \\
\text { distribution and elimination }\end{array}$ \\
\hline & & Slow absorption (SC, IM) \\
\hline & & Very long half-life \\
\hline \multirow[t]{2}{*}{ Concentration-effect relationship } & Existence of interindividual variability & Mechanism of action \\
\hline & & Sources of variability \\
\hline \multirow[t]{3}{*}{ Clinical pharmacology studies } & & Analytical techniques \\
\hline & & Complex pharmacokinetics models \\
\hline & & Biological markers \\
\hline
\end{tabular}

SC: subcutaneous route; IM: intramuscular route.

secondary to Allogeneic Stem Cell Transplantation. Cell therapy except for mainly HSC transplantation, is still at the proof of concept stage and it is difficult to apply the methodology of the various phases I, II or III of clinical drug development. However, the conditions for initiation and development of this cell therapy are now defined by European Directives which consider that most products, either autologous or allogeneic, are medicinal products. In view of the specificity of these products, technical guidelines are currently being elaborated at the European level. This field does not include HSC and certain cell preparation intended for a limited number of patients, for which the regulatory framework remains specific to each country.

\subsection{In vivo gene therapy}

In vivo gene therapy consists of the administration of viral or non-viral vectors in order to genetically modify cells. This type of treatment, still in the experimental stage, was therefore not discussed in detail by the round table. This therapy is based on the use of vectors or macromolecule with a perfectly defined structure which can therefore be considered as biopharmaceuticals.

\section{Conclusion}

The participants of the round table recommend avoiding use of the generic term "Biotherapy" in order to clearly distinguish biopharmaceuticals from cell therapy and gene therapy. In the field of biopharmaceuticals, the round table essentially discussed therapeutic antibodies and fusion proteins and a number of recommendations concerning these agents can therefore be proposed. A summary of the common points and differences between therapeutic antibodies and conventional medicinal products is proposed in Table I.

The design of phase I studies and other phases of development must be revised due to the limited information provided by preclinical studies. A complementary scientific expertise, especially immunological, is necessary during preclinical and clinical development.

Finally, the first Marketing Authorisation represents only the beginning of the knowledge on the therapeutic antibody, as it is also necessary to:

- combine biological collections with cohort follow-up;

- perform complementary studies in order to more clearly define the place of the biopharmaceutical in treatment and its modalities of prescription;

- ensure prescriber information in order to improve individual patient follow-up.

\section{Participants}

François Amalric (INCa, Paris), François Bassompierre (DRC de l'AP-HP, Paris), Laurent Becquemont (Pharmacologie, CHU Paris Sud), Guillaume Cartron (Onco-Hématologie, CHU Montpellier), Dominic Cellier (Merck, Paris), Georges Dagher (INSERM, Paris), Thierry Demerens (CNAMTS), Alain Dessein (Parasitologie, CHU Marseille), Danièle Girault (Wyeth, 
La Défense), Jean-Marc Grognet (CEA Saclay, Gif-sur-Yvette), Vincent Le Gros (Novartis, Rueil-Malmaison), François Lemoine (Immunologie, UPMC et GH Pitié-Salpêtrière, Paris), Laurence Moachon (Pharmacologie, GH Cochin-Port Royal), Marc Pallardy (Faculté de Pharmacie, Chatenay-Malabry), Atul Pathak (Pharmacologie, CHU Toulouse), Marc Peschanski (INSERM/ISTEM, Evry), Lionel Ségard (Quantum Genomics, Massy), Patrick Squiban (Innate Pharma, Marseille), Daniel Vasmant (Cancéropôle Ile-de-France), Luc Vermeesch (UCB Pharma, Bruxelles), Hervé Watier (EA3853 et Immunologie, CHU Tours), Pierrette Zorzi (Afssaps).

\section{References}

1. Clergeot A, Arnoux PY, Lassale C. Biomédicaments en France : état des lieux en 2004. La Lettre du Pharmacologue 2005; 19: 74-81

2. Suntharalingam G, Perry MR, Ward S, et al. Cytokine storm in a phase 1 trial of the anti-CD28 monoclonal antibody TGN1412. N Engl J Med 2006; 355 : 1018-28

3. Final report on TGN1412 clinical trial. Medicines and Healthcare products Regulatory Agency, United Kingdom, 25/05/2006. http:// www.mhra.gov.uk/home/idcplg?IdcService=SS_GET_PAGE\&use Secondary=true \&ssDocName $=$ CON2023822\&ssTargetNodeId $=389$

4. Ohresser M, Olive D, Vanhove B, et al. Risk in drug trials. Lancet 2006; 368: 2205-6

5. Loisel S, Ohresser M, Pallardy M, et al. Relevance, advantages and limitations of animal models used in the development of monoclonal antibodies for cancer treatment. Crit Rev Oncol Hematol 2007; 62: 34-42

6. Food and Drug Administration. Center for Drug Evaluation and Research (CDER). Guidance for Industry: Estimating the maximum safe starting dose in initial clinical trials for therapeutics in adult healthy volunteers. Juillet 2005. http://www . fda.gov/CDER/GUIDANCE/5541fnl.htm

7. Direction de l'évaluation des médicaments et des produits biologiques. Département de l'évaluation des médicaments à statut particulier et des essais cliniques. Essais cliniques de première administration à l'Homme, en dose unique d'un médicament expérimental (nouvelle substance active) : Choix de la première dose, de la progression de dose et protocole d'administration aux volontaires. Afssaps, 05/09/2006. http://agmed.sante.gouv.fr/pdf/3/essais-clinique-phase1.pdf

8. Expert Scientific Group (ESG) on phase one clinical trials. Final report. Department of Health, United Kingdom, december 2006. http://www.dh.gov.uk/assetRoot/04/14/10/43/04141043.pdf

9. Chung KY, Shia J, Kemeny NE, et al. Cetuximab shows activity in colorectal cancer patients with tumors that do not express the epidermal growth factor receptor by immunohistochemistry. J Clin Oncol 2005; 23: 1803-10
10. Cartron G, Dacheux L, Salles G, et al. Therapeutic activity of humanized anti-CD20 monoclonal antibody and polymorphism in $\mathrm{IgG} \mathrm{Fc}$ receptor FcgammaRIIIa gene. Blood 2002; 99: 754-8

11. Louis E, El Ghoul Z, Vermeire S, et al. Association between polymorphism in IgG Fc receptor IIIa coding gene and biological response to infliximab in Crohn's disease. Aliment Pharmacol Ther 2004; 19: 511-9

12. Miescher S, Spycher MO, Amstutz H, et al. A single recombinant anti-RhD IgG prevents RhD immunization: association of RhD-positive red blood cell clearance rate with polymorphisms in the FcgammaRIIA and FcgammaIIIA genes. Blood 2004; 103: 4028-35

13. Ternant D, Paintaud G. Pharmacokinetics and concentration-effect relationships of therapeutic monoclonal antibodies and fusion proteins. Expert Opin Biol Ther 2005; 5: S37-S47

14. Baert F, Noman M, Vermeire S, et al. Influence of immunogenicity on the long-term efficacy of infliximab in Crohn's disease. N Engl J Med 2003; 348: $601-8$

15. Maini RN, Breedveld FC, Kalden JR, et al. Therapeutic efficacy of multiple intravenous infusions of anti-tumor necrosis factor alpha monoclonal antibody combined with low-dose weekly methotrexate in rheumatoid arthritis. Arthritis Rheum 1998; 41: 1552-63

16. St Clair EW, Wagner CL, Fasanmade AA, et al. The relationship of serum infliximab concentrations to clinical improvement in rheumatoid arthritis: results from ATTRACT, a multicenter, randomized, double-blind, placebocontrolled trial. Arthritis Rheum 2002; 46: 1451-9

17. Yim DS, Zhou H, Buckwalter M, et al. Population pharmacokinetic analysis and simulation of the time-concentration profile of etanercept in pediatric patients with juvenile rheumatoid arthritis. J Clin Pharmacol 2005; 45: 246 56

18. Lee H, Kimko HC, Rogge M, et al. Population pharmacokinetic and pharmacodynamic modeling of etanercept using logistic regression analysis. Clin Pharmacol Ther 2003; 73: 348-65

19. Berinstein NL, Grillo-Lopez AJ, White CA, et al. Association of serum rituximab (IDEC-C2B8) concentration and anti-tumor response in the treatment of recurrent low-grade or follicular non-Hodgkin's lymphoma. Ann Oncol 1998; 9: 995-1001

20. Igarashi T, Kobayashi Y, Ogura M, et al. Factors affecting toxicity, response and progression-free survival in relapsed patients with indolent B-cell lymphoma and mantle cell lymphoma treated with rituximab: a Japanese phase II study. Ann Oncol 2002; 13: 928-43

21. Hale G, Rebello P, Brettman LR, et al. Blood concentrations of alemtuzumab and antiglobulin responses in patients with chronic lymphocytic leukemia following intravenous or subcutaneous routes of administration. Blood 2004; 104: 948-55

Correspondence and offprints: Gilles Paintaud, Laboratoire de Pharmacologie-Toxicologie et EA3853, CHRU de Tours, 2 boulevard Tonnellé, 37044 Tours Cedex 9, France.

E-mail: paintaud@med.univ-tours.fr 